\title{
Microwave Radiometer Linearity Measured by Simple Means
}

\section{Skou, Niels}

\section{Published in:}

Proceedings of IEEE International Geoscience and Remote Sensing Symposium

Link to article, DOI:

10.1109/IGARSS.2002.1027284

Publication date:

2002

Document Version

Publisher's PDF, also known as Version of record

Link back to DTU Orbit

\section{Citation (APA):}

Skou, N. (2002). Microwave Radiometer Linearity Measured by Simple Means. In Proceedings of IEEE International Geoscience and Remote Sensing Symposium (pp. 3664-3667). IEEE.

https://doi.org/10.1109/IGARSS.2002.1027284

\section{General rights}

Copyright and moral rights for the publications made accessible in the public portal are retained by the authors and/or other copyright owners and it is a condition of accessing publications that users recognise and abide by the legal requirements associated with these rights.

- Users may download and print one copy of any publication from the public portal for the purpose of private study or research.

- You may not further distribute the material or use it for any profit-making activity or commercial gain

- You may freely distribute the URL identifying the publication in the public portal 


\title{
Microwave Radiometer Linearity Measured by Simple Means
}

\author{
Niels Skou \\ Oersted $•$ DTU, B 348, Technical University of Denmark. \\ DK 2800 Lyngby, Denmark. \\ Phone: (45) 452538 00, Fax: (45) 4593 16, e-mail: ns@oersted.dtu.dk
}

\begin{abstract}
Modern spaceborne radiometer systems feature an almost perfect on-board calibration, hence the primary calibration task the be carried out before launch is a check of radiometer linearity. This paper describes two ways of measuring linearity of microwave radiometers only requiring relatively simple equipment.
\end{abstract}

\section{INTRODUCTION}

This paper deals with alternatives to the traditional way of calibrating radiometers. The traditional method is based on the principle of pointing the radiometers feed horn towards a variable temperature, scene simulating target. Although conceptually simple it is not technically simple. The target must exhibit excellent VSWR and be variable in temperature over a large range with extreme precision $(\sim 0.1 \mathrm{~K})$. Such a target is expensive and moreover its operation is expensive as it requires thermal vacuum environment.

The on-board calibration in present spaceborne radiometer systems - like the well known SSM/I - is carried out in an almost ideal fashion: the feed horn cluster sequentially view the main offset parabolic reflector for the actual measurement of scene properties, the hot load for one calibration point, and the cold sky reflector for a second calibration point. The output of the hot load is known by careful measurements of the physical temperature of the absorbing elements, and by design taking into consideration the emmisivity of the load and the VSWR of the load in conjunction with the noise temperature of the radiometers as seen through the feeds. The output from the main reflector is the antenna temperature modified by the main reflector loss. This loss can be quantified very accurately, [1]. The output from the cold reflector is the sky temperature, which is known by design (feed/reflector radiation pattern, satellite geometry, orbit geometry), modified by the cold reflector loss. No VSWR problems are foreseen for the two reflector cases due to the offset geometry. Thus, as the losses and physical temperatures of the two reflectors are known with good accuracy, a perfect calibration takes place. This is in strong contrast to most earlier radiometer systems where a switch matrix selects whether the antenna, the hot load, or the separate sky horn is connected to the radiometer receiver. This result in large problems with losses, switch isolations, and the fact that different signal paths when calibrating and when measuring the antenna temperature must be sustained. Ground calibration in this case becomes an intriguing exercise in determining all possible losses, isolations, and radiometer transfer function properties. In the first case, however, due to the "perfect" calibration scheme, the ground calibration exercise would be non existing if the radiometers were known to be perfectly linear!

Unfortunately the radiometers cannot be assumed perfectly linear, so the main task of the ground calibration is to determine the transfer function of the radiometers with sufficient accuracy, (plus the precise determination of the losses in the two reflectors which is not the subject here).

\section{SIMPLE 3-POINT CALIBRATION}

The purpose of this calibration procedure is to make a rough calibration of the radiometers and check their linearity with good accuracy yet using simple, low-cost, primary targets. The principle is illustrated in Fig. 1. Two targets made of Eccosorb material in isolated metal buckets are used. Filling liquid nitrogen into a target provides a cold calibration temperature $\mathrm{T}_{\mathrm{C}}(\sim 77 \mathrm{~K})$ and leaving it without the liquid nitrogen provides the hot calibration temperature $\mathrm{T}_{\mathrm{H}}\left(=\mathrm{T}_{0} \sim\right.$ 293 K). Two identical antennas are connected with equal waveguides to a magic tee, the radiometer is connected to the sum port while the difference port is terminated. The power from one antenna is split between the sum and difference ports.

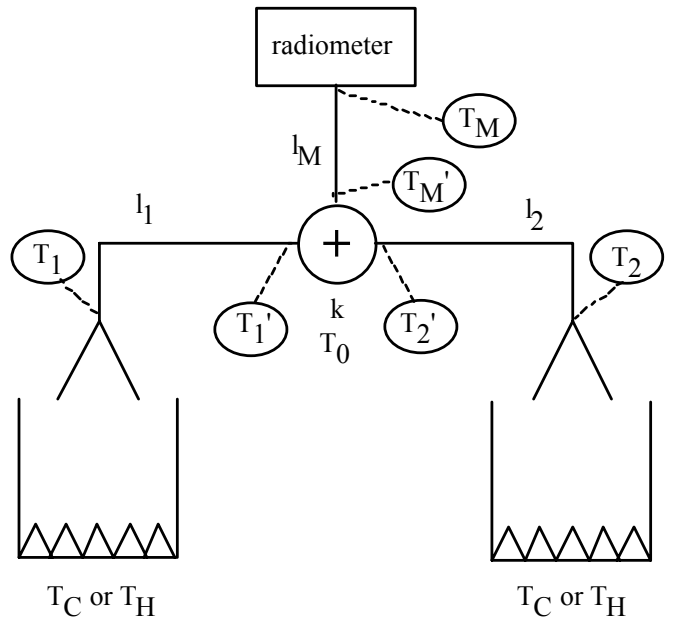

Fig. 1: Set-up for simple 3-point calibration

As the signals from the two antennas are uncorrelated, the sum port will provide to the radiometer the average value of 
the two antenna signals (in the ideal, lossless case and with an ideal, symmetrical magic tee). The noise signal from the termination is split equally between the two antennas.

The calibration procedure includes four cases: the hot case $(\mathrm{HH})$ where both antennas view $\mathrm{T}_{\mathrm{H}}$ and the radiometer measures $\mathrm{T}_{\mathrm{H}}$, the cold case (CC) where both antennas view $\mathrm{T}_{\mathrm{C}}$ and the radiometer measures $\mathrm{T}_{\mathrm{C}}$, and two mixed cases ( $\mathrm{CH}$ and $\mathrm{HC}$ ) where one antenna views $\mathrm{T}_{\mathrm{C}}$ the other $\mathrm{T}_{\mathrm{H}}$ and the radiometer measures $\left(\mathrm{T}_{\mathrm{C}}+\mathrm{T}_{\mathrm{H}}\right) / 2$ or $\left(\mathrm{T}_{\mathrm{H}}+\mathrm{T}_{\mathrm{C}}\right) / 2$ that are equal in the ideal case.

It is assumed that the transfer function of the radiometer looks like the "possible situation" shown in Fig. 2. It is a very likely situation considering the way a radiometer is built. A dominating factor in the transfer function will be the square law detector. It is something between square law and linear, and "good" square law behavior is obtained for sufficiently low signal levels. A transfer function like the "impossible situation" shown in Fig 2 cannot be dealt with by the calibration method under discussion here. It is not a likely situation, and for many good reasons it must be avoided. Returning to the likely function of Fig. 2 and the procedure described above, it will in the following be shown that one can measure 3 points on the calibration curve with good accuracy even under non-ideal conditions i.e. lossy components and non-perfect balance in the magic tee ( $\mathrm{k}$ is not 0.5 ).

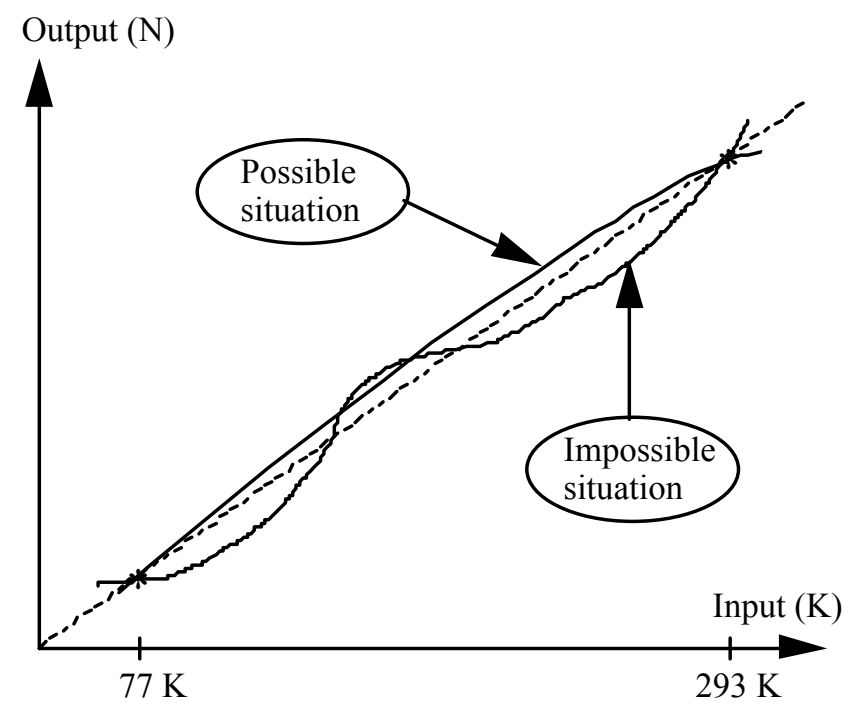

Fig. 2: Radiometer calibration curves

By inspection of Fig. 1 the following set of equations can be established:

$$
\begin{aligned}
& \mathrm{T}_{1}{ }^{\prime}=\mathrm{T}_{1} \cdot \mathrm{l}_{1}+\left(1-\mathrm{l}_{1}\right) \cdot \mathrm{T}_{0} \\
& \mathrm{~T}_{2}{ }^{\prime}=\mathrm{T}_{2} \cdot \mathrm{l}_{2}+\left(1-\mathrm{l}_{2}\right) \cdot \mathrm{T}_{0} \\
& \mathrm{~T}_{\mathrm{M}^{\prime}}=\mathrm{k} \cdot \mathrm{T}_{1}{ }^{\prime}+(1-\mathrm{k}) \cdot \mathrm{T}_{2}{ }^{\prime}
\end{aligned}
$$

$$
\mathrm{T}_{\mathrm{M}}=\mathrm{T}_{\mathrm{M}}{ }^{\prime} \cdot \mathrm{l}_{\mathrm{M}}+\left(1-\mathrm{l}_{\mathrm{M}}\right) \cdot \mathrm{T}_{0}
$$

By proper insertion the following expression for the input to the radiometer is found:

$\mathrm{T}_{\mathrm{M}}=\mathrm{k} \cdot \mathrm{l}_{\mathrm{M}} \cdot \mathrm{l}_{1} \cdot \mathrm{T}_{1}+\mathrm{k} \cdot \mathrm{l}_{\mathrm{M}} \cdot\left(1-\mathrm{l}_{1}\right)+(1-\mathrm{k}) \cdot \mathrm{l}_{\mathrm{M}} \cdot \mathrm{l}_{2} \cdot \mathrm{T}_{2}+(1$ $-\mathrm{k}) \cdot \mathrm{l}_{\mathrm{M}} \cdot\left(1-\mathrm{l}_{2}\right) \cdot \mathrm{T}_{0}+\left(1-\mathrm{l}_{\mathrm{M}}\right) \cdot \mathrm{T}_{0}$

Let's assume the hot case: $\mathrm{T}_{1}=\mathrm{T}_{2}=\mathrm{T}_{\mathrm{H}}=\mathrm{T}_{0}$, and by insertion and reduction we find:

$\mathrm{T}_{\mathrm{M}}{ }^{\mathrm{HH}}=\mathrm{T}_{0}$ which is not surprising!

By letting $\mathrm{T}_{1}=\mathrm{T}_{2}=\mathrm{T}_{\mathrm{C}}$ in equation (5) we find an expression for the radiometer input in the cold case: $T_{M}{ }^{C C}$. Likewise, $\mathrm{T}_{1}=\mathrm{T}_{\mathrm{H}}=\mathrm{T}_{0}$ and $\mathrm{T}_{2}=\mathrm{T}_{\mathrm{C}}$ gives $\mathrm{T}_{\mathrm{M}}{ }^{\mathrm{HC}}$, while $\mathrm{T}_{1}=$ $\mathrm{T}_{\mathrm{C}}$ and $\mathrm{T}_{2}=\mathrm{T}_{\mathrm{H}}=\mathrm{T}_{0}$ gives $\mathrm{T}_{\mathrm{M}}{ }^{\mathrm{CH}}$. By proper insertion and reduction it is straight forward to show that the average value $\mathrm{T}_{\mathrm{M}}{ }^{\text {av }}$ of $\mathrm{T}_{\mathrm{M}}{ }^{\mathrm{HC}}$ and $\mathrm{T}_{\mathrm{M}}{ }^{\mathrm{CH}}$ is equal to the mid point value $\mathrm{T}_{\mathrm{m}}$ of $\mathrm{T}_{\mathrm{M}}{ }^{\mathrm{HH}}$ and $\mathrm{T}_{\mathrm{M}}{ }^{\mathrm{CC}}$, i.e.:

$$
\left(\mathrm{T}_{\mathrm{M}}{ }^{\mathrm{HC}}+\mathrm{T}_{\mathrm{M}}{ }^{\mathrm{CH}}\right) / 2=\left(\mathrm{T}_{\mathrm{M}}{ }^{\mathrm{HH}}+\mathrm{T}_{\mathrm{M}}^{\mathrm{CC}}\right) / 2
$$

so, with our radiometer under test we measure the extreme (hot and cold) cases - $\mathrm{T}_{\mathrm{M}}{ }^{\mathrm{HH}}$ and $\mathrm{T}_{\mathrm{M}}{ }^{\mathrm{CC}}$ - we calculate the mid point value $\mathrm{T}_{\mathrm{m}}$, and we expect the radiometer to yield this value as an average $\mathrm{T}_{\mathrm{M}}$ av of the two measurements of the mixed (hot/cold, cold/hot) cases. If not the radiometer is nonlinear.

A precondition for this to be able to work is that there is reasonable balance in the system i.e. $\mathrm{k} \approx 0.5$ which means that $\mathrm{T}_{\mathrm{M}}{ }^{\mathrm{HC}} \approx \mathrm{T}_{\mathrm{M}}{ }^{\mathrm{CH}}$, and that the radiometer has a "decent" nonlinear characteristic.

A sensitivity analysis is warranted. Assume the magic tee imbalance to be $\pm 0.1 \mathrm{~dB}$ corresponding to $\mathrm{k}=0.51$. Assume equal length waveguides so that $1_{1}=1_{2}=1_{M}=0.95$ (corresponding to $0.2 \mathrm{~dB}$ loss). Let $\mathrm{T}_{\mathrm{H}}=\mathrm{T}_{0}=293 \mathrm{~K}$ and $\mathrm{T}_{\mathrm{C}}=$ $77 \mathrm{~K}$. We can then calculate that $\mathrm{T}_{\mathrm{M}} \mathrm{HH}=293 \mathrm{~K}, \mathrm{~T}_{\mathrm{M}} \mathrm{CC}^{\mathrm{C}}=$ 98.06 K, and the mid point value $\mathrm{T}_{\mathrm{m}}=195.53 \mathrm{~K}$. Likewise we find $\mathrm{T}_{\mathrm{M}}{ }^{\mathrm{HC}}=197.48 \mathrm{~K}$ and $\mathrm{T}_{\mathrm{M}}{ }^{\mathrm{CH}}=193.58 \mathrm{~K}$. The average value is $\mathrm{T}_{\mathrm{M}}$ av $=195.53 \mathrm{~K}$ as we would have expected. It is seen that a realistic imbalance will result in a small difference in the $T_{M}$ values i.e. we can average the results from a slightly nonlinear radiometer and thus get a measurement of the deviation from linearity midway between $\mathrm{T}_{\mathrm{C}}$ and $\mathrm{T}_{\mathrm{H}}$.

Further comments: $1_{1}, 1_{2}$ and $l_{M}$ include the ohmic losses in the 3 ports of the magic tee. Lack of isolation between the difference port and the sum port will result in loss of some signal to the termination and generation of some signal in the sum port from the termination i.e. just like loss in the transmission line between the tee and the radiometer. Hence, 
this effect can be regarded as included in $l_{M}$ and, as the calculations show, has no effect in the present case.

It shall be noted that the calibration method under discussion does not solve the problem of finding the transfer function below $77 \mathrm{~K}$, which could be a problem as the cold calibration point in space is only a few Kelvins.

\section{LINEARITY CHECKED BY SLOPE MEASUREMENTS}

Fig. 3 shows another set-up by which a roughly calibrated radiometer can be checked for linerarity. An antenna horn points towards a simple liquid nitrogen target and a variable attenuator (Att2) with low insertion loss and at ambient temperature are able to produce any brightness temperature from $\sim 77 \mathrm{~K}$ to $\sim 293 \mathrm{~K}$. The accurate value of the brightness temperature is not known but can be assessed by the roughly calibrated radiometer. Through a directional coupler with a coupling value of $20 \mathrm{~dB}$ (in order not to attenuate the signal in the main arm unduly) a noise signal of variable amplitude is injected. The signal originates in a noise diode (typical excess noise ratio, ENR larger than $20 \mathrm{~dB}$ ) and is attenuated in a variable attenuator Att1. A PIN diode switch selects either this signal or the signal from a load at ambient for injection.

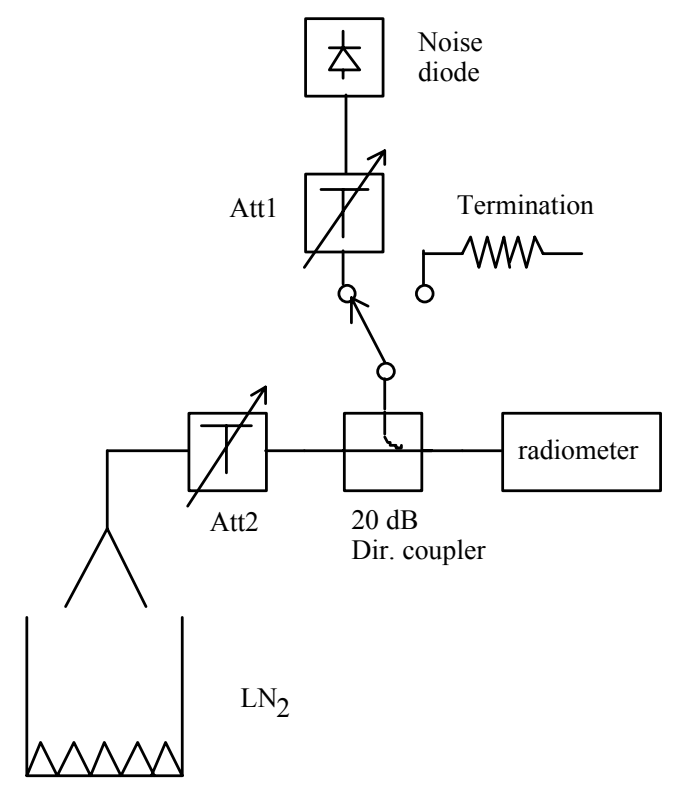

Fig. 3: Slope measurement set-up

When the ambient load is on, the net result is that practically no extra noise is added to the signal from the antenna horn, while as the switch selects the signal from the noise diode a certain noise is added. The attenuators could be of the rotary vane type for low insertion loss and good stability.

Fig. 2 shows the transfer function for the radiometer under test. By the rough calibration two points are established corresponding (as an example) to $77 \mathrm{~K}$ and $293 \mathrm{~K}$. For simplicity the calibration constant $\left(\mathrm{N} / \mathrm{T}_{\mathrm{i}}\right)$ is assumed equal to 1. If the transfer function is linear (dashed curve) then the output change $\Delta \mathrm{N}$ corresponding to a certain setting of Att1, hence a certain input change $\Delta \mathrm{T}_{\mathrm{i}}$, will be the same for all settings of Att2, hence all values of $T_{i}$. This is not the case if the transfer function is not linear.

Let's assume a "nice" curve that deviates 0.1 from the linear curve midway between the two known calibration points (shown strongly exaggerated as the "possible" curve). An input of $185 \mathrm{~K}$ will result in an output of 185.1. If we select Att1 to give $\Delta \mathrm{T}_{\mathrm{i}}=108 \mathrm{~K}$ we will observe a $\Delta \mathrm{N}$ of 108.1 and 107.9 for two suitable settings of Att2.

This difference of 0.2 corresponding in the present example to $0.2 \mathrm{~K}$ can be clearly detected. Hence, by this method we can readily detect deviations from a linear curve down to the $0.1 \mathrm{~K}$ level. Actually, we can measure the true deviation and assess the transfer function by proper selection of attenuator settings.

It is noteworthy that if the antenna horn is pointed towards the sky the check can be extended almost down to the cold calibration point in space.

\section{MEASUREMENTS}

\section{A. 3-Point Method}

A noise injection radiometer (NIR), a Dicke radiometer (DR), and a total power radiometer (TPR), all Ka band, have been subjected to linearity checks as described in Section II. In fact the NIR and DR cases are not independent as we deal with one Dicke type switching radiometer able to operate in both modes. Fig. 4 shows an example of the experiments with the NIR instrument. First the hot case is measured to $\mathrm{T}_{M} \mathrm{HH}=$ $295.10 \mathrm{~K}$. Then follows, after filling one target with liquid nitrogen, a series of cold-hot / hot-cold combinations by moving the targets around. We find $\mathrm{T}_{\mathrm{M}} \mathrm{HC}=188.43 \mathrm{~K}$ and $\mathrm{T}_{\mathrm{M}} \mathrm{CH}=191.11 \mathrm{~K}$ (averages over the 3 measurements of each). Hence $\mathrm{T}_{\mathrm{M}}{ }^{\mathrm{av}}=189.77 \mathrm{~K}$. Filling the second target with nitrogen enables the 3 measurements of the cold case, and $\mathrm{T}_{\mathrm{M}} \mathrm{CC}=88.17 \mathrm{~K}$. Finally is shown a case where a low loss horn is connected directly to the radiometer input and pointed to the cold target to yield $77.27 \mathrm{~K}$ as result. This, together with the hot case, provides the basic calibration of the radiometer. From the hot and the cold case is seen that the mid point value is $\mathrm{T}_{\mathrm{m}}=191.64 \mathrm{~K}$, meaning that there is a deviation from linearity of $1.87 \mathrm{~K}$ halfway between the hot and cold calibration point! 


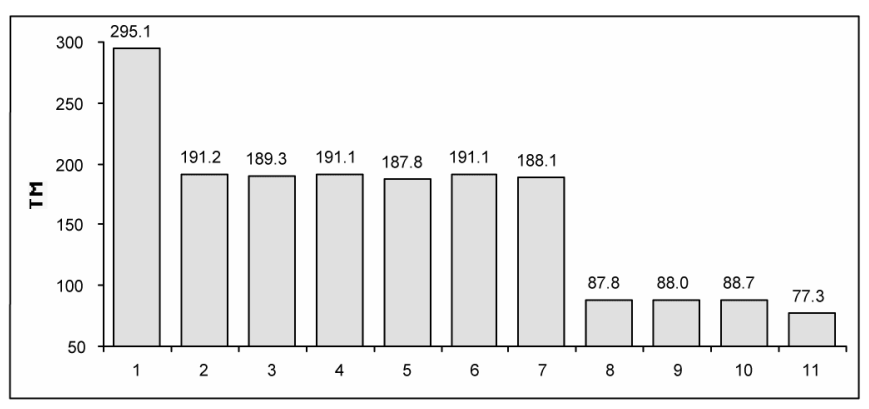

Fig. 4: Example of NIR 3-point experiment

As stated earlier several experiments with different radiometer types were carried out, and representative examples are summarized in Table 1.

Table 1: Summary of experiments (values in Kelvin)

\begin{tabular}{|c|c|c|c|c|c|}
\hline & $\mathrm{T}_{\mathrm{M}}{ }^{\mathrm{HH}}$ & $\mathrm{T}_{\mathrm{M}}{ }^{\mathrm{CC}}$ & $\mathrm{T}_{\mathrm{M}^{\mathrm{av}}}$ & $\mathrm{T}_{\mathrm{m}}$ & Diff. \\
\hline NIR\#a & 295.1 & 88.2 & 189.8 & 191.6 & 1.9 \\
\hline NIR\#b & 299.2 & 91.2 & 193.2 & 195.2 & 2.0 \\
\hline DR\#a & 298.1 & 91.0 & 192.7 & 194.6 & 1.9 \\
\hline DR\#b & 294.1 & 89.9 & 190.1 & 192.0 & 1.9 \\
\hline TPR\#a & 294.3 & 91.0 & 192.8 & 192.7 & -0.1 \\
\hline TPR\#b & 294.1 & 90.7 & 192.5 & 192.4 & -0.1 \\
\hline
\end{tabular}

It is seen that the NIR and the DR consistently reveals a non-linear behavior, while the TPR is quite linear. The first hardware is from the 1970'es based on a Shottky diode detector, while the TPR is a recent development with a high quality tunnel diode detector. It is seen that the NIR and DR calibration curves bend upwards and not downwards as would be the case if the cause for nonlinarity were compression in low frequency circuitry or the fact that the detector law were somewhere between 2 and 1 (between square and linear law). However, Shottky detector diodes are known to be able to exhibit a transfer law exceeding square law (exponent more than 2) in the transition region between square and linear under certain impedance conditions. This is probably the case here.

\section{B. Slope Method}

Only the TPR has been examined by the slope method. The reason is that this radiometer already by design includes circuitry for injecting noise at the input for calibration purposes. Thus only an attenuator between the radiometer and the antenna horn is needed to realize the setup of Fig. 3 (with the limitation that only one value of injected noise is possible as Att 1 is not present). Table 2 shows results from one experiment. By measuring liquid nitrogen and an internal calibration load, the radiometer is calibrated the usual way. The value of the injected noise is $\Delta \mathrm{T}_{\mathrm{i}}=161.2 \mathrm{~K}$ at low levels. The attenuator is set at different values with some (unknown) accuracy, but the cold point is measured by the now calibrated radiometer.

Table 2: Slope measurements

\begin{tabular}{|c|c|c|c|}
\hline & Att 2 & Cold point & $\delta T_{\mathrm{B}}$ \\
\hline $\mathrm{a}$ & 0 & $77 \mathrm{~K}$ & $161.2 \mathrm{~K}$ \\
\hline $\mathrm{b}$ & $0.15 \mathrm{~dB}$ & $92.9 \mathrm{~K}$ & $161.3 \mathrm{~K}$ \\
\hline $\mathrm{c}$ & $0.3 \mathrm{~dB}$ & $130.1 \mathrm{~K}$ & $161.1 \mathrm{~K}$ \\
\hline $\mathrm{d}$ & $0.45 \mathrm{~dB}$ & $182.4 \mathrm{~K}$ & $160.7 \mathrm{~K}$ \\
\hline
\end{tabular}

It is seen that at first (steps a through c) the injection of the noise results in the same change in radiometer output indicating the linear behavior we expect from the 3-point measurements. The measurement uncertainty is some $0.1 \mathrm{~K}$ based on experience from repeated experiments. The last attenuator setting (d) reveals beginning compression, but note that the injected noise brings the total input to the radiometer up to $343.1 \mathrm{~K}$ which is beyond the design limit corresponding to natural Earth targets (one might say that this is a marginal design).

\section{DISCUSSION AND CONCLUSIONS}

The calibration methods described in this paper are not able to deal with a full calibration of a non-linear radiometer having arbitrary transfer characteristic. However, the methods are well suited for checking of linearity down to low levels and they may be used to assess the calibration curve for a radiometer that is slightly nonlinear in a neat fashion (second order curve not deviating much from a linear curve).

The 3-point calibration method is the simplest seen from a hardware point of view. All that is needed is a magic tee, 2 horn antennas, 2 targets and a few waveguide sections. On the other hand it is probably the most demanding to handle. One measurement sequence as illustrated in Fig. 4 takes some 20 minutes, and care must be exercised to ensure stability over that time span.

The slope method requires more advanced hardware as a stable noise diode is required (if not already built into the radiometer). On the other hand the experiments are easier and quicker to carry out resulting in fewer potential error sources.

\section{REFERENCES}

[1] N. Skou, "Measurement of small antenna reflector losses for radiometer calibration budget," IEEE Trans. Geoscience and Remote Sensing, Vol. 35, No. 4, July 1997, pp. 967 - 971. 